Published by Al-Nahrain College of Medicine P-ISSN 1681-6579

E-ISSN 2224-4719

Email: iraqijms@colmed-alnahrain.edu.iq

http://www.colmed-alnahrain.edu.iq

http://www.iraqijms.net

Iraqi JMS 2018; Vol. 16(3)

\title{
The Interstitium (The Pre-lymphatic Region), Is It a Newfound 'Organ'
}

\author{
Hayder J. Mubarak $P h D$ \\ Dept. of Human Anatomy, College of Medicine, Al-Nahrain University, Baghdad, Iraq
}

\begin{abstract}
Many of the human anatomists wouldn't expect to discover a new body part, however, researchers claim that they found a network of fluid-filled spaces in connective tissues all over the body that hadn't been seen before and it acts like an "open, fluid-filled highway" that is supported by a lattice of thick collagen "bundles".

The researchers stated that tissue fixation during the procedure of histological tissue processing causes collapse of this network of fluid-filled spaces, and these spaces were not seen during light microscopic examination till the new imaging technique were developed to allow examination of living tissues on a microscopic level.
\end{abstract}

Keywords Interstitium, anatomy, neworgan, cancer

Citation Mubarak HJ. The Interstitium (the pre-lymphatic region), is it a newfound 'organ'. Iraqi JMS. 2018; 16(3): 230-231. doi: 10.22578/IJMS.16.3.1

List of abbreviation: None

\section{Introduction}

$\mathrm{R}$ esearchers in 2018 reported the description of a network of fluid-filled spaces in connective tissues all over the body as an organ called (the interstitium). This description utilized the examination of the living tissue by the power of confocal laser endo-microscopy. This technique combines an endoscope with a laser, and sensors that showed the spaces where fluid accumulates, those spaces are pre-lymphatic and appeared to drain into lymph nodes ${ }^{(1)}$.

This finding may have many implications in fields of medicine, including cancer research. It may explain why cancer can spread to the lymph nodes, as this fluid - filled spaces are a source of the fluid (called lymph) drained into the lymphatic system (2). When cancer cells metastasized through the blood stream or the lymph system, the interstitium spaces may act as conduits, and thus direct sampling of the interstitial fluid may be a proper diagnostic tool for cancer researches ${ }^{(1)}$.

The human body contains about 60 percent water, two-thirds of this water is intra-cellular, and one-third is extra-cellular (known as "interstitial" fluid). The interstitial tissue and interstitial fluid are well known in medical biology. The interstitial" fluid is estimated to form about $20 \%$ of body volume, which is equivalent to about 10 liters in a young adult (3).

The new insights suggested that the (interstitial fluid) is a previously unrecognized feature of human anatomy and raising the idea of calling the interstitium an "organ". The newly described interstitial spaces were suggested to be important possibly in many aspects as, generating the supportive collagen, housing stem cells, or playing a role in conducting electrical signals during cellular movements and stretch. The interstitium likely acts as a 
kind of shock absorber for the rest of our interior ${ }^{(1)}$.

The traditional histopathological biopsy sampling involved dehydration of tissue samples, and the interstitium is collapsed by dehydration and appeared as a dense layer when examined after traditional histopathological tissue preparation ${ }^{(4)}$. When the tissue samples were quickly frozen, it allowed the fluid-filled spaces could be seen under a microscope ${ }^{(1)}$.

\section{Is interstitium as an organ a pseudoscientific belief, or a fact?}

Calling interstitium as "organ" is one of the controversies among scientists, the other is about the idea that this discovery could explain many of modern medicine's mysteries.

Many have the feeling of a bit of déjà vu for this discovery. Recently, researchers reported also the discovery of "new" organ: the mesentery! (5).

In order to illuminate answers for these debates, the definition of an organ needs to be settled ${ }^{(6)}$. Does human body have 79 organs, or 80 organs, or 1,000 organs. The number depends on the definition of what an organ actually is. No two anatomists will agree on a list of organs in the body.

Googling "what is an organ"? Results suggested that (an organ is composed of two or more tissues, is self-contained and performs a specific function). While, tissue is defined as (the structure made from specific and similar type of cells that are grouped or organized together and assigned to perform the specific function).
In consideration to debates of anatomist to the definition of the term (organ), we must report that all the body parts are important regardless of whether being called as organ or not. We still need it to function.

In conclusion; the distinction for the interstitium as an (organ) needs further investigations in order to clarify the possible changes that may be associated with / or altered in this organ during disease, and to establish whether this organ have a role in driving diseases.

\section{References}

1. Benias PC, Wells RG, Sackey-Aboagye B, et al. Structure and distribution of an unrecognized interstitium in human tissues. Sci Rep. 2018; 8(1): 4947. doi: 10.1038/s41598-018-23062-6.

2. Rofstad EK, Galappathi K, Mathiesen BS. Tumor Interstitial Fluid Pressure-A Link between Tumor Hypoxia, Microvascular Density, and Lymph Node Metastasis. Neoplasia. 2014; 16(7): 586-94. doi: 10.1016/j.neo.2014.07.003.

3. Johnson HL, Virk SP, Mayclin P, et al. Predicting total body water and extracellular fluid volumes from bioelectrical measurements of the human body. J Am Coll Nutr. 1992; 11(5): 539-47.

4. Chatterjee S. Artefacts in histopathology. J Oral Maxillofac Pathol. 2014; 18(Suppl 1): S111-6. doi: 10.4103/0973-029X.141346.

5. Coffey JC, O'leary DP. Defining the mesentery as an organ and what this means for understanding its roles in digestive disorders. Expert Rev Gastroenterol Hepatol. 2017; 11(8): 703-705. doi: 10.1080/17474124.2017.1329010.

6. Neumann PE. Another new organ. is this a golden age of discovery in anatomy? Clin Anat. 2018; 31(5): 6489. doi: 10.1002/ca.23184.
E-mail: hayder_67_67@yahoo.com hjkmubarak@colmed-alnahrian.edu.iq 